KAWISTARA

VOLUME 4

No. 3, 22 Desember 2014

Halaman 225-330

\title{
FUNGSI LAGU PERJUANGAN SEBAGAI PENDIDIKAN KARAKTER BANGSA
}

\author{
Wisnu Mintargo \\ Institut Seni Indonesia Surakarta \\ Email: wisnumintargo@isi-ska.ac.id \\ RM. Soedarsono \\ Universitas Gadjah Mada \\ Victor Ganap \\ Institut Seni Indonesia Yogyakarta
}

\begin{abstract}
Patriotic songs basically originated from the history of education in Indonesia, starting from intellectual circle and teachers in pre-independence era initiated by the Boedi Oetomo movement (1908), the 1928 Youth Pledge and post 1945 independence. The form and meaning of the patriotic songs, either on vocals or with instruments, take place in ceremonial activities and performance art. According to Alan M. Meriam and RM. Soedarsono, this applies to public school, the Indonesian Air Force, and Gelora Bahana Patria Choir. As for character education, the specialty of Yogyakarta reflects its identity as a city of struggle, city of education and city of arts and culture. According to the theory of transformation, something new, including the arrangements of patriotic songs in the forms of march, hymn, romance for parade, military defile and aubade, is to restore the spirit of nationalism and patriotism. The success of transforming the patriotic songs so as to have new atmosphere is dependent on the various abilities to make the arrangement works, so that they can draw attention from the doers and the listeners and function in ceremony and performance art. In line with the Decree of the Ministry of National Education of 2011 items 10 and 11 regarding the values of nationalism and patriotism, we can realize those values by singing patriotic songs, using Indonesian language as the unifying language, and acknowledging, appreciating and commemorating the services of national heroes.
\end{abstract}

Keywords: Songs of Indonesia Struggle, National and Charracter Buliding

\section{ABSTRAK}

Lagu-lagu patriotik pada dasarnya berasal dari sejarah pendidikan di Indonesia, mulai dari kalangan intelektual dan guru diera pra-kemerdekaan yang diprakarsai oleh gerakan Boedi Oetomo (1908), 1928 Sumpah Pemuda dan pascakemerdekaan 1945. Bentuk dan makna dari lagu-lagu patriotik, baik pada vokal atau dengan instrumen, berlangsung dalam kegiatan upacara dan seni pertunjukan. Menurut Alan M. Meriam dan RM. Soedarsono, ini berlaku untuk sekolah negeri, Angkatan Udara Indonesia, dan Gelora Bahana Patria Choir. Adapun pendidikan karakter, khusus Yogyakarta mencerminkan identitasnya sebagai kota perjuangan, kota pendidikan dan kota seni dan budaya. Menurut teori transformasi, sesuatu yang baru, termasuk pengaturan dari lagu-lagu patriotik dalam bentuk pawai, himne, roman untuk parade, ngarai militer dan Aubade, adalah untuk mengembalikan semangat nasionalisme dan patriotisme. Keberhasilan mengubah lagu-lagu patriotik sehingga memiliki suasana baru tergantung 
pada berbagai kemampuan untuk membuat karya-karya pengaturan, sehingga mereka dapat menarik perhatian dari para pelaku dan pendengar dan fungsi dalam upacara dan seni pertunjukan. Sejalan dengan Keputusan Menteri Pendidikan Nasional tahun 2011 item 10 dan 11 tentang nilainilai nasionalisme dan patriotisme, kita dapat mewujudkan nilai-nilai dengan menyanyikan lagulagu patriotik, menggunakan bahasa Indonesia sebagai bahasa pemersatu, dan mengakui, menghargai dan memperingati jasa pahlawan nasional.

\section{Kata Kunci: Lagu Indonesia Perjuangan, Nasional dan Charracter Buliding}

\section{PENGANTAR}

Lagu perjuangan Indonesia dikenal dengan istilah musik fungsional yaitu musik diciptakan untuk tujuan nasional. Lagu perjuangan adalah kemampuan daya upaya yang muncul lewat media kesenian dan berperan aktif di dalam peristiwa sejarah kemerdekaan Indonesia. Pengertian yang luas lagu perjuangan sebagai ungkapan persaan semangat kebangsaan dan cinta tanah air yang diungkapkan melalui lagu-lagu.

Pada masa perjuangan bangsa Indonesia di masa pra kemerdekaan 1928 dan pasca kemerdekaan 1945 sebagaian besar lagu-lagu perjuangan diciptakan oleh para guru dan cendekiawan tujuannya adalah mengusir penjajah guna merebut kemerdekaan. Perkembangan musik diatonik sebagai musik nasional diakui oleh bangsa Indonesia pada sumpah pemuda dan sekaligus berkumandangnya lagu Indonesia Raya ciptaan W.R. Supratman sebagai simbol persatuan pembentukan bangsa Indonesia.

Pada masa perjuangan perkembangan musik diatonis sebagai sarana pendidikan nasional terjadi seiring munculnya generasi muda setelah W.R. Supratman dan M. syafei pendiri I.N.S. Kayu Tanam di Sumatera Barat, dari masa pra kemerdekaan 1928 beralih ke masa pasca kemerdekaan 1945 yaitu kelompok pemusik asal daerah Tapanuli dengan latar belakang musik gereja misionaris Jerman yang cukup handal. Para pemusik terkenal ialah Cornel Simanjuntak (Guru dan Komponis), Amir Pasaribu
(Guru dan Komponis), J.A. Dungga (Guru \& Kritikus), L. Manik (Guru dan Komponis), Binsar Sitompul (Guru dan Komponis), Alfred Simanjuntak (Guru \& Komponis), W. Lumban Tobing (Etnomusikologi) dan Nortier Simanungkalit (Guru dan Komponis).

Di Jawa dikenal Ismail Marzuki (Komponis), Kusbini (Guru dan Komponis) Bintang Sudibyo (Guru dan komponis), R.A.J. Sudjasmin(GurudanKomponis), danlain-lain. Pemusik ini tidak hanya beranggapan bahwa budaya musik sebagai alat perjuangan yang dapat diterima oleh berbagai kebhinekaan bangsa Indonesia namun sekaligus sebagai alat perjuangan dan pendidikan karakter bangsa. Menurut Pardosi Siagian sejak tahun 1975 hingga saat ini tercatat sebanyak 180 lagu-lagu perjuangan yang berkembang di Indonesia. Jenis dan bentuk lagu-lagu ini kemungkinan akan bertambah sesuai dengan kebutuhan dan perkembangan jaman. Lagulagu perjuangan sebagai karya cipta adalah bentuk single part song form, contohnya lagu Bagimu Neg'ri, twoe part song form contohnya Satu Nusa Satu Bangsa, three part song form contohnya lagu Indonesia Raya atau Sepasang Mata Bola terangkum dalam jenis musik Himne, Mars dan Romans.

Permasalahan yang dihadapi makna yang terkandung dalam nila-nilai semangat kebangsaan dan cinta tanah air, saat ini mengalami pasang surut akibat perubahan oleh karena kemajuan era globalisasi. Derasnya arus globalisasi, akibatnya bangsa Indonesia mengalami tantangan diantara citacita mengisi kemerdekaan dan kehidupan sehari-hari. Nilai-nilai nasionalisme mendegradasi dan bisa mengancam persatuan dan kesatuan bangsa, untuk itu diupayakan agar para pelajar, mahasiswa, aparatur negara dan masyarakat memiliki kesadaran kebangsaan dan cinta tanah air, salah satu cara ialah mengumandangkan kembali lagu perjuangan Indonesia dalam pertemuan dan kegiatan tertentu dimasa perubahan ini, agar tidak dilupakan oleh generasi penerus hingga akhir zaman.

Walikota Herry Zudianto (2008) menetapkan kota Yogyakarta sebagai kota kebang- 
saan, kota perjuangan, dan kota merah putih. Ketetapan ini diberlakukan dengan membuat peraturan daerah yang mengatur penanaman nilai-nilai kebangsaan dan perjuangan dalam masyarakat di lingkungan kota Yogyakarta. Pendidikan karakter adalah salah satu unsur yang dipakai dalam menumbuhkan semangat kebangsaan dan cinta tanah air. Alasan kota Yogyakarta dijadikan tempat membangun, nilai dan jiwa kebangsaan karena latar belakang sejarah sebagai kota perjuangan, terutama peranannya sangat penting pada masa revolusi kemerdekaan. Dalam suasana revolusi di Yogyakarta pada tahun 19461949 menjadi pusat pemerintahan Republik Indonesia, serta pusat komando perjuangan rakyat indonesia melawan Kolonial Belanda dan sekutunya dilancarkan dari Yogyakarta. Peristiwa-peristiwa penting menunjukan perjuangan, terutama perjuangan para pemuda di Yogyakarta dan terciptanya lagulagu perjuangan.

Tujuan yang ingin dicapai dalam penulisan ini untuk mengetahui sejauh mana peranan lagu perjuangan bagian dari sistem pendidikan karakter bangsa yang diajarkan di sekolah umum, di imnstansi militer maupun di masyarakat Yogyakarta yang perlu ditingkatkan kualitasnya. Secara umum penggunaan lagu-lagu perjuangan di kota Yogyakarta sampai saat ini tumbuh subur oleh karena kebinekaan masyarakatnya mencerminkan identitas keistimewaan Yogyakarta sebagai kota perjuangan, kota pendidikan, kota budaya dan pariwisata. Subtansi yang digambarkan pada lagu-lagu perjuangan, bahwa pesan moral dan keterlibatan hati yang disampaikan ternyata semakin relevan sepanjang waktu bukan semakin pudar dan jauh dari tuntutan jaman. Semakin sering lagu itu diperdengarkan semakin lama keharuan dan juga keinginan untuk menerapkan nilai-nilai yang ada pada lagu itu semakin besar.

Solusisaat ini untuk mengisi kemerdekaan pembangunan nasional kadar kepahlawanan semangat cinta tanah air tidak selalu diukur dengan keterlibatan dalam perang mengangkat senjata, tetapi keberhasilan diukur dalam prestasinya memerangi kemiskinan, keterbelakangan bangsa, serta melawan ketidak adilan dan korupsi di Indonesia. Salah satu tantangan besar pada lagu-lagu perjuangan adalah bagaimana potensi itu bisa meningkatkan kualitas sumberdaya manusia Indonesia saat ini yang mampu melahirkan pahlawanpahlawan muda di bidang pendidikan mencetak tenaga ahli, terampil berkualitas tinggi sehingga sejajar dengan bangsabangsa lain (Martono, 1953: 668).

Tinjauan pustaka penulis mencermati tentang lagu-lagu perjuangan yang dilakukan oleh para peneliti sebelumnya. Dari hasil penelitian itu ternyata dapat diketahui bahwa generasi muda di kota Yogyakarta sebagian besar kurang memahami arti dan makna dari lagu-lagu tersebut. Di sisi lain sesuatu yang baru peranan lagu-lagu perjuangan selain sebagai sarana pendidikan karakter berfungsi juga sebagai suatu sistem baru dalam tes penerimaan siswa baru pada jenjang tingkat lanjutan. Lagu-lagu perjuangan di kota Yogyakarta dipakai sebagai sarana materi ujian masuk jenjang tingkat SMP dan SMA dengan materi tes menyanyi sambil menjadi dirigen untuk dipertimbangkan diterima pada kriteria tertentu terutama bagi sekolah umum yang berstatus swasta. Peluang ini juga dapat dimanfaatkan oleh sekolah umum, instansi militer dan masyarakat dalam kegiatan vokal maupun instrumendalam bentuk arransemen baru lagu-lagu perjuangan agar generasi muda lebih mencintainya.

\section{PEMBAHASAN \\ Pendidikan Karakter Semangat Kebangsaan dan Cinta Tanah Air}

Didalam pendidikan karakter ada kewajiban untuk menghayati lagu-lagu perjuangan, karena lagu tersebut diciptakan oleh komponis Indonesia yang hidup dimasa perjuangan. Menunjukan adanya sebuah proses perubahan di dalam gerakan perjuangan menuju kemerdekaan yang digambarkan oleh lagu-lagu tersebut. Setiap lagu tentunya mempunyai nilai sejarah, sehingga berkaitan langsung antara lagu itu dengan peristiwa perjuangan. Peranan 
lagu-lagu perjuangan dalam pembentukan karakter bangsa, digambarkan bahwa perjuangan bangsa Indonesia sudah dilakukan berabad-abad yang lalu dimulai pada masa pra kemerdekaan hingga pasca kemerdekaan. Jadi intinya kemerdekaan itu adalah sebuah proses sejarah yang tidak dapat dilupakan oleh bangsa Indonesia.

Pendidikan karakter dalam pendidikan nasional baru bisa dipahami manfaatnya bila lagu-lagu perjuangan selalu berkaitan dengan perilaku dan ilmu pengetahuan seperti kewarganegaraan, Ilmu Sosial membahas sejarah dan Bahasa Indonesia. Sesuai Pendidikan Budaya dan karakter bangsa Kementerian Pendidikan Nasional 2011 butir 10 dan 11 nilai-nilai semangat kebangsaan dan kecintaan pada tanah air, salah satu dibahas menyanyikan lagu perjuangan, berbahasa Indonesia sebagai bahasa persatuan, serta menegenal dan menghargai para para pahlawan nasional melalui lagulagu perjuangan maupun dalam simulasi pelajaran sejarah bangsa berperan sebagai transformasi (Bhaedowi, 2011: 7). Di perlukan guru-guru PKN yang dapat memahami arti dan makana, upacara bendera, pembacaan teks pembukaan UUD 45, Teks Pancasila dan fungsi lagu upacara dan lagu-lagu aubade di pagi hari ketika upacara diberlakukan bagi sekolah umum. Guru Bahasa Indonesia dapat memahami arti dan makna teks lagu kebangsaan Indonesia Raya, serta teks lagulagu perjuangan berdasarkan analisis bentuk sastra. Guru sejarah dalam Ilmu Sosial dapat memahami peristiwa penting pelajaran sejarah dalam konteks lagu-lagu perjuangan yang diperdengarkan dalam kelas maupun dalam aubade. Konsep ini sangat berkaitan dengan teori Patriotisme Peter B. Heller tentang nilai kecintaan tanah air merupakan nilai-nilai kebenaran bagi suatu bangsa dalam membela dan mempertahankan negara (Heller, 1996: 951).

Menurut Soekarno kemerdekaan adalah kebebasan untuk merdeka yaitu kebebasan untuk menjalankan urusan politik, ekonomi, dan sosial budaya tanpa interpensi asing. Permasalahannya ada dua jenis penjajahan model baru di Indonesia yang dapat mempengaruhi kehidupan berbangsa dan bernegara yaitu neokolonialisme eksternal dan internal. Secara eksternal pasca kemerdekaan bangsa Indonesia pada tahun 1961 konfrensi dewan kesetiakawanan Asia Afrika diingatkan bahwa Neo Kolonialisme adalah bentuk yang perlu diwaspadai yaitu penguasaan tidak langsung secara halus melalui sistem politik, ekonomi sosial budaya, militer dan teknik. Hal ini dilakukan untuk menciptakan kekacauan dengan menghasut pemisahan wilayah demi kepentingan negara asing dengan konflik-konflik baru, Sebagai pertahanan wilayah kedaulatan masa reformasi ditegaskan dalam Peraturan Presiden No. 78 tahun 2005 ada 12 pulau terluar Indonesia yang menjadi perhatian khusus pemerintah. Masih segar dalam ingatan bangsa ketika Indonesia kalah dari Malaysia dalam memperebutkan pulau Sipadan dan Ligitan karena dinilai pemerintah tidak pernah memberi perhatian terhadap pulau tersebut.Oleh karena lemahnya pengawasan pemerintah Indonesia sehingga lepasnya pulau Sipadan dan Ligitan dari pangkuan ibu pertiwi tanggal 17 Desember 2002. Belajar dari pengalaman, generasi muda di pulau-pulau terluar menjadi garda terdepan membangun daerah dan meningkatkan rasa nasionalisme dalam meningkatkan pertahanan.

Secara internal sebagai wujud cinta tanah air dalam tiga dekade terakhir mahasiswa mengalami pertumbuhan secara pesat dan mereka selalu berjuang sebagai oposisi melawan rezim yang berkuasa. Pada tahun 1966 gerakan mahasiswa berkobar di bawah panji Tritura bubarkan PKI. Bagaimana pun mahasiswa mempunyai peran besar melahirkan orde baru, tetapi ketika orde baru berdiri, mahasiswa dipinggirkan dari arena politik dengan dalih stabilitas politik. Mereka menentang dikotomi ekonomi antara sikaya dan simiskin, kekuasaan politik antara yang kuat dan yang lemah. Reformasi belum mampu keluar dari konflik lokal yang berkepanjangan seperti alat perlawanan yang kebablasan diluar ambang batas. Di masa peristiwa reformasi gerakan aksi mahasiswa 
Indonesia. Pada 12 Mei sampai dengan 17 Desember 1998 bahwa menyanyikan lagulagu perjuangan salah satu berfungsi sebagai alat perlawanan oposisi menentang ketidak adilan, korupsi dan nepotisme hingga runtuhnya rezim orde baru. Sampai saat ini lagu-lagu perjuangan masih relevan sebagai alat perjuangan untuk menegakkan keadilan seperti melawan korupsi adalah sebagai bentuk baru mendorong semangat gerakan KPK memberantas korupsi di Indonesia, serta meningkatkan pertahanan budaya sebagai jati diri bangsa bagi masyarakat.di pulau terluar wilayah perbatasan NKRI.

Lagu-lagu perjuangan bersifat instrumental untuk upacara adalah yang dilakukan TNI di kota Yogyakarta, setiap saat dan acara tertentu. Musik instrumen yang diperdengarkan antara lain Lagu kebangsaan Indonesia Raya berfungsi sebagai penghormatan lambang negara, Bagimu Neg'ri untuk pelantikan jabatan yang bersifat kenegaraan, Hari Merdeka berfungsi sebagai musik parade senja, Maju tak Gentar berfungsi sebagai musik parade dan defille, Andika Bhayangkara sebagai lagu penutup laporan upacara yang bersifat militer bahwa amanat yang disampaikan pimpinan dapat dipahami seluruh peserta upacara untuk menjalankan tugas negara. Kegiatan upacara ini merupakan bagian dari pembentukan karakter bangsa untuk membentuk rasa disiplin, patuh dan taat kepada pimpinan aparatur negara sebagai pengabdian tanpa pamrih.

Lagu-lagu perjuangan sebagai pertunjukan aubadedalam bentuk paduan suara adalah sama seperti dilakukan Paduan suara Gelora Bahana Patria dan sekolah umum berkaitan dengan kegiatan upacara yang diselenggarakan pada pagi hari misalnya upacara sekolah, upacara hari besar nasional, pada pertemuan kongres kebangsaan dan kegiatan sosial lainnya yang berlangsung di kota Yogyakarta. Perbedaan kedua kelompok terletak pada kemampuan menyanyikannya dalam bentuk arransemen empat suara pada paduan suara Gelaora Bahana Patria, sedang untuk usia sekolah tingkat SD, SMP, SMA cara menyanyikannya secara umum masih bersifat unisono dan lagu- lagu yang diperdengarkan adalah sebagai berikut. Lagu kebangsaan Indonesia Raya, berfungsi sebagai lagu pengibaran sang saka merah putih atau lagu pembukaan, Bagimu Neg'ri sebagai lagu penutup kegiatan belajar, Indonesia Subur, Bangun Pemudi-pemuda, Berkibarlah benderaku, Sepasang mata bola, Satu Nusa Satu Bangsa,.dan lagu perjuangan lainnya merupakan lagu-lagu untuk aubade.Aubade adalah musik yang diperdengarkan pada pagi hari dalam suatu upacara tertentu, nyanyian masal di lapangan terbuka ditempatkan panggung pertunjukan sebagai suatu persembahan kehormatan (Sadie, 2001: 153).

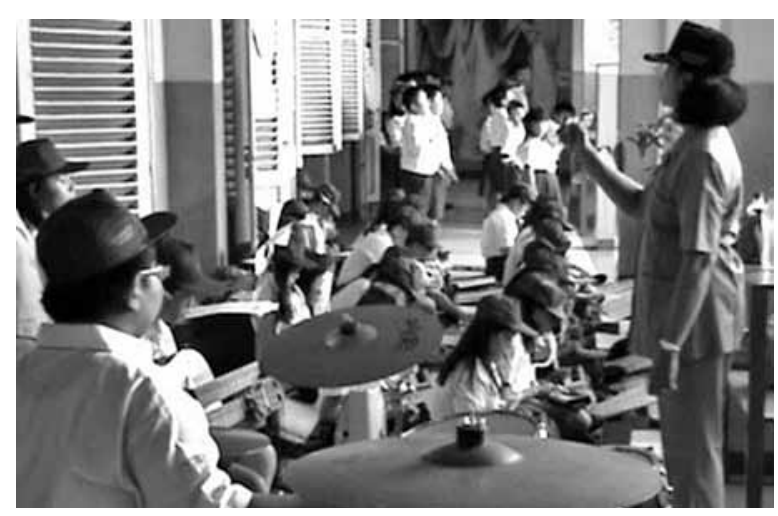

\section{Gambar 1}

Upacara Aubade Lagu Berkibarlah Benderaku SD Marsudirini 22 April 2013 Memperingati Hari Kartini (Photo Wisnu Mintargo)

Upaya mengamankan lagu perjuangan sebagai kekayaan bangsa dan memperoleh payung hukum yang memadai. Dalam hal ini Peranan TNI/Polri amatlah penting untuk itu harus diakui bahwaSatuan Musikyang dimiliki TNIberdirisejak masa pasca kemerdekaan telah berjasa besar dalam mengamankan keberadaan lagu-lagu perjuangan.Berdirinya Korps musik TNI dan Polri pada umumnya tidak lepas dari peranan Kesultanan Kraton Yogyakarta Sri Sultan HB IX, para personilnya menyebar membentuk keasatuan baru Korps Musik di daerah lain. Setelah Indonesia merdeka pada tahun 1950 Sri Sultan Hemengku Buwono IX Kraton Orcest Djogja di pimpin Raden Rio Soerjowaditra dbubarkan dianggap sebagai warisan Kolonial. Sri Sultan dengan penuh kearifan lalu mengibahkan instrumen musik Barat kepada para pemusik Kraton sebagai 
bekal untuk mengembangkan profesinya hingga menyebar membentuk kesatuan baru didaerah lain, diantaranya di unit kesatuan POLRI, TNI AD, TNI, AU dan TNI Al (Ganap, 2008: 17).

Prosesi upacara selain penghormatan lagu kebangsaan, musik parade dipakai untuk unjuk gelar dalam suatu upacara militer yang dirancang atau ditata dalam bentuk tertentu guna menerima wejangan atau maupun menyampaikan penghormatan kebesaran (Bonoe, 2003: 323). Bagi Satuan Korp Musik TNI lagu-lagu perjuangan merupakan repertoar wajib dan menjadi bagian yang tidak dipisahkan dari tugas operasional TNI. Tidak dapat dipungkiri bahwa satuan Musik menempati garda terdepan dalam menjaga dan menegakkan panji-panji negara dalam bentuk lagu-lagu perjuagan berperan aktif dalam pelaksanaan upacara bersifat sipil maupun militer. Bangsa Indonesia sepatutnya berterimakasih kepada TNI/Polri yang senantiasa berupaya meningkatkan kualitas Korp Musik secara professional melalui pemberdayaan personil, seperti wajib militer maupun militer sukarela bagi lulusan sarjana musik untuk dididik sebagai perwira TNI/Polri.

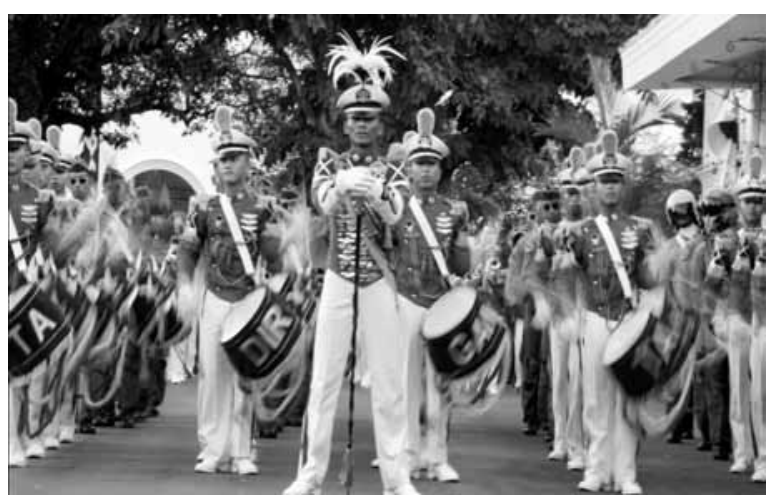

Gambar 2

Parade Senja17 Agustus 2013 Lagu Hari Merdeka Drumband AAU Gita Dirgantara di Gedung Agung Yogyakarta (Photo Wisnu Mintargo).

Vidya Karma Vira Pakca, merupakan salah satu doktrin pembentukan karakter militer yang menjiwai pelaksanaan pendidikan Karbol (bersih), agar dapat mencapai tujuan. Di jelaskan bahwa setiap karbol dalam melaksanakan tugas belajar dituntut dengan penuh disiplin yang tinggi dan penuh tanggung jawab. Menciptakan prajurit Karbol yang bermental dan bermoral yang baik, dengan melakukan upaya peningkatan frekueensi dan kualitas pembinaan mental guna membentuk mental karbol yang dijiwai oleh Pancasila, Sapta Marga, dan Sumpah Prajurit. Sehingga diharapkan dapat menjadi seorang perwira TNI yang dapat memimpin anak buah, serta dapat memimpin bangsa dan Negara. Para karbol bukanlah orang yang berbakat bermain musik mereka dipersiapkan menjadi penerbang yang tanggap dalam penalaran, tanggon memilik kepribadian yang dapat diandalkan serta trengginas terampil dan tangkas dalam brtindak. Kegiatan musik merupakan bagian pendidikan karakter dari kegiatan kreatif ajang gelar sesuai motto AAU dalam mengekspresikan atraksi seni untuk mengisi kegiatan hari besar nasional serta pengabdian kepada masyarakat sebagai simbol kebanggaan Akademi TNI Angkatan Udara dengan selalu menggelorakan lagulagu mars perjuangan berfungsi sebagai musik perang.Musik yang mengiringi parade barisan upacara biasanya diperdengarkan musik mars seperti lagu Maju Tak Gentar Musik defille adalah bentuk baris berbaris yang digunakan dalam kesatuan militer agar pelaksanaannya berjalan tertib, teratur dan disiplin dengan tempo gerakan yang sama maka diperlukan musik pengiring dari satuan musik militer atau drumband untuk menunjukkan kemampuan baris berbaris prajurit di depan para pimpinan, dengan menampilkan unit kesatuan barisan penuh semangat, gagah berani dan musik yang dipakai adalah musik mars.

Paduan suara Gelora Bahana Patria dalam hal ini terbukti dapat diandalkan untuk melaksanaan amanat ini, karena pengalamannya berjuang tanpa pamrih dalam mengisi kemerdekaan dan mencerdaskan bangsa melalui lagu-lagu perjuangan. Pendidikan karakter guna memupuk dan membangkitkan semangat kebangsaan sebagai benteng bagi identitas an kepribadian bangsa. 
Paduan suara Gelora Bahana Patria adalah organisasi berdasarkan kebinekaan yang yang tumbuh bedasarkan semangat kebangsaan dan cinta tanah air yang berdiri sejak tahun 1964 yaitu paduan suara mahasiswa Bahana patria oleh N.Simanungkalit sebagai pendiri dan dibantu anggota Gerakan Mahasiswa Nasional Indonesia (GMNI) di Pusat Olah Vokal Dinas pendidikan dan Kebudayaan Daerah Istimewa Yogyakarta menetapkan misi dan visi untuk mengumandangkan lagu-lagu perjuangan dan lagu-lagu daerah, guna turut membina wawasan kebangsaan di kalangan masyarakat. Pada tahun 1964 Nortier Simanungkalit dibantu oleh Priyo Dwiarso mendidrikan pula paduan Suara Pelajar Gerakan Siswa Nasional Indonesia (GSNI) Gelora patria. Pada tahun 1990 diadakan reuni Akbar di Jakarta diikuti lebih 200 alumni bertekad untuk melanjutkan visi misi 1964 dengan nama Paduan Suara Gelora Bahana Patria (PS.GBP) dan pusat latiahan berada di Jakarta dan Yogyakarta. Kini Paduan Suara gelora Bahana Patria tetap konsisten dengan lagu-lagu perjuangan serta mengemban misi memperkuat jiwa kebangsaan menuju kepribadian nasional agar bangsa Indonesia memiliki identitas kepribadian dan jati diri bangsa sebagai bangsa pejuang.

Paduan Suara Gelora Bahana Patria organisasi kesenian yang saat ini masih tumbuh subur di ditengah-tengah masyarakat Yogyakarta, telah menyadari semakin merosotnya apresiasi jenis musik paduan suara, perlu adanya kegiatan yang menggairahkan olah paduan suara agar pelestarian lagulagu perjuangan dan lagu-lagu daerah dapat dilanjutkan oleh generasi berikutnya. Paduan suara Gelora Bahana Patria yang dirintis oleh pelajar dan mahasiswa di Yogyakarta sejak tahun 1964 adalah jenis olah musik yang dapat memenuhi unsur estetika dan etika budaya yang dapat memberi komsumsi jiwa positif kepada pelaku dan pendengarnya. Perlu kesinambungan gairah apresiasi olah paduan suara dari generasi kini kepada generasi muda dalam rangka "Nation and Character Building" yang berkelanjutan (Sudarto, 2011: 2).

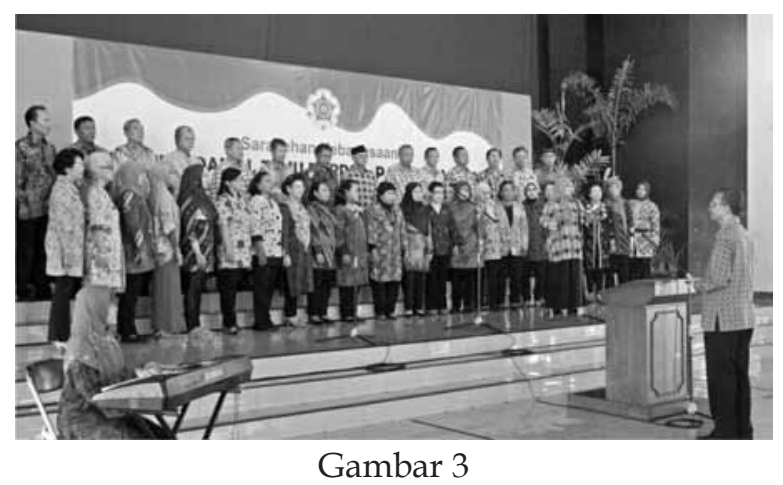

Indonesia Raya oleh Paduan Suara Gelora Bahana Patria dalam Acara Sarasehan Kebangsaan Sosialisasi Pemilu Damai PSP UGM 1 Februari 2014(Photo Wisnu Mintargo)

\section{SIMPULAN}

Berdasarkan uraian tersebut diatas teori yang dikemukakan Peter B. Heller patritiotism (cinta tanah air) sebagai suatu nilai kebenaran dan sesuatu yang baru dalam penelitian ini sebagai berikut. lagu-lagu perjuangan untuk upacara dan pertunjukan aubade adalah lagu-lagu yang dapat membangkitkan semangat kebangsaan dan rasa cinta tanah air, memiliki arti nilai-nilai penegakan demokrasi yang berkeadilan. Subtansi yang digambarkan pada lagulagu perjuangan bahwa pesan moral dan keterlibatan hati yang disampaikan ternyata semakin relevan sepanjang waktu bukan semakin pudar dan jauh dari tuntutan jaman. Semakin sering lagu itu diperdengarkan semakin lama keharuan dan juga keinginan hati nurani untuk menerapkan nilai-nilai yang ada pada lagu itu semakin besar.

Sejarah perjuangan membuktikan bahwa lagu-lagu perjuangan masa revolusi salah satu pendorong semangat melawan penjajahan. Namun demikian makna lagulagu perjuangan saat ini masih relevan walaupun situasi mengalami perubahan yaitu untuk mengisi kemerdekaan. Berdasarkan peraturan pemerintah tahun 1959 berfungsi menanamkan nilai-nilai nasionalisme dan cinta tanah air yang diajarkan dan ditanamkan kepada generasi penerus dalam upacara maupun seni pertunjukan. Lagulagu perjuangan sudah mulai diajarkan pada tingkat pendidikan dasar hingga perguruan 
tinggi, sesuai rekomendasi kongres pancasila V di UGM Yogyakarta tanggal 1 Juni 2013. Dalam menghadapi tantangan dan hambatan saat ini setiap upacara bendera dan pembacaan teks Pancasila selalu diperdengarkan aubade lagu-lagu perjuangan.

Transformasi lagu-lagu perjuangan adalah sebuah gambaran perjuangan masa pra kemerdekaan dan masa pasca kemerdekaan yang sering dikumandangkan dalam upacara dan seni pertunjukan. Arransemen lagu-lagu perjuangan adalah sebuah kreativitas yang diwujudkan dalam bentuk vokal maupun instrumen sebagai jiwa perjuangan yang harus dipelihara dan dilestarikan sebagai ekspresi semangat kebangsaan dan cinta tanah air. Keberhasilan lagu-lagu perjuangan saat ini terletak pada kemampuan dan kekuatan arrransemen yang dapat menarik perhatian para pendengarnya sehingga lagu tersebut bervariatif, tidak membosankan, seolah-olah seperti lagu baru dan hidup dihati sanubari bangsa sepanjang masa.

Pasca-orde baru lagu-lagu perjuangan digelorakan para mahasiswa Indonesia masa reformasi sebagai cinta tanah air membela kebenaran terhadap perlawanan demokrasi dan anti korupsi, sampai saat ini lagulagu tersebut menjadi bagian dari gerakan mahasiswa di Yogyakarta. Sebaliknya Bagi pemerintah lagu-lagu perjuangan terus dipakai sebagai alat sosialisai pesan pemerintah untuk pembangunan etos kerja melalui media massa, radio, dan televisi. Sebagai pendidikan karakter di sekolah umum rasa cinta tanah air lagu-lagu perjuangan diwujudkan melalui pemahaman sejarah berguna bagi generasi penerus bangsa agar tidak melupakan sejarah Indonesia. Selain itu sebagai pencitraan tidak kalah menarik saat ini partai politik telah menggunakan lagu-lagu perjuangan sebagai alat kampanye dan menyebarluaskan visi dan misi partai agar dapat menarik massa.

\section{DAFTAR PUSTAKA}

Baedhowi. 2011. Pendidikan Karakter Bangsa Dengan Pendekatan Nilai-nilai Seni
Budaya Edisi Pertama. Direktur Jendral PMPTK Kemendiknas Jakarta.

Banoe. Ponoe, 2003. Kamus Musik Edisi Pertama, cetak pertama. Kanisius Yogyakarta.

Heller. P:eter B., 1996. “Patriotism” dalam Frank N. Magill, ed. International Encyclopedia of Government and Politicks, Volume 2 Toppan PTE.Singapore.

Ganap, Victorius, 2008. Sumbangsih Ilmu Pengetahuan Musik Dalam Pembentukan Jatidiri Bangsa. Pidato Pengukuhan Sebagai Guru Besar Fakultas Seni Pertunjukan ISI 19 Januari 2008. Yogyakarta.

Martono, Sri,. 1953. Kehidupan Seni Suara Tahun 1945-1952 Edisi Pertama, Cetak Pertama Kementerian Penerangan Republik Indonesia Yogyakarta.

Sadie, Stanley. 2001. The Grove Dictiomaryof Music E Musicians. Publisher Limited Vol.2 Macmillan. New York

Soewindi, Djoko. 2013. Rekomendasi Komisi 1 Bidang Pendidikan Kongres Pancasila V.PSP UGM 31 Mei Yogyakarta.

Sudarto, Tyasno. 2011. “Peran Lagu Perjuangan Dalam memupuk dan Membangkitkan Semangat Kebangsaan" Makalah dalam Sarasehan Dalam Rangka Memperingati Hari Kebangkitan Nasional. TMII 23 Mei Jakarta.

\section{Discografi}

“Tragedi Jakarta 1998 Gerakan Aksi Mahasiswa di Indonesia" Film Dokumenter Cerita \& Narasi Tino Sarenggallo.Produksi Jakarta Media Syndication, 2000.

“Upacara Bendera di Pulau Marore dan Bepondi 17 agustus 2009". Acara Metro Realitas 28 Agustus 2009. Narasi Evi Juliani Produksi Metro TV Jakarta 